\title{
Islas fluviales en el bajo Ebro en época medieval (siglos XII y XIII)
}

\author{
River islands in the lower Ebro in medieval times \\ (12th and 13th centuries)
}

\section{Helena KIRCHNER y Antoni VIRGILI}

Authors:

Helena Kirchner

Catedràtica d'Història Medieval. Departament de Ciències de l'Antiguitat i de l'Edat Mitjana. Universitat Autònoma de Barcelona (Barcelona, Spain)

helena.kirchner@uab.cat

https://orcid.org/0000-0002-3877-4138

Antoni Virgili

Professor Agregat d'Història Medieval. Departament de Ciències de l'Antiguitat i de l'Edat Mitjana. Universitat Autònoma de Barcelona (Barcelona, Spain)

antoni.virgili@uab.cat

https://orcid.org/0000-0001-5952-9791

Date of reception: 13/04/21

Date of acceptance: 28/05/21

Citation:

Kirchner, H. y Virgili, A. (2021). Islas fluviales en el bajo Ebro en época medieval (siglos XII y XIII). Anales de la Universidad de Alicante. Historia Medieval, (22), 27-55. https://doi.org/10.14198/medieval.19542

Funding: Este artículo se ha elaborado en el marco del proyecto Órdenes agrarios y conquistas ibéricas (siglos XII-XVI). Estudios desde la arqueología histórica (HAR2017-82157-P), Ministerio de Economía, Industria y Competitividad.

(C) 2021 Helena Kirchner y Antoni Virgili Colet

Licence: This work is licensed under a Creative Commons Attribution 4.0 International License (CC BY 4.0).

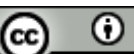

\section{RESUMEN}

La investigación llevada a cabo en los últimos diez años en el bajo Ebro ha permitido, a partir del análisis de la documentación y mediante recursos arqueológicos, estudiar los espacios agrarios de ribera vinculados a los asentamientos rurales andalusíes y a Madīnat Ṭurțūša, así como las transformaciones producidas en estos espacios a raíz de la colonización feudal tras la conquista cristiana, en 1148. En la documentación escrita destacan las referencias a algeziras o insulae para referirse a unos espacios de ribera fluvial rodeados total o parcialmente por brazos del río, fácilmente inundables y sujetos a modificaciones frecuentes aunque lo bastante estables como para suscitar el interés para explotar sus recursos y por su posterior ocupación y colonización. En época andalusí, salvo excepciones, estos espacios no fueron objeto de cultivo permanente, sino de aprovechamiento de los recursos naturales que ofrecía la vegetación de ribera, en especial, pastos. Tras la conquista, los señores feudales impulsaron significativas transformaciones en los espacios agrarios ya existentes. Se promocionó el cultivo de los cereales y la viña, pero destacan especialmente los procesos de roturación de las áreas incultas. Entre estas se cuentan amplios sectores en la llanura deltaica, pero también algunos espacios de ribera, como las algeziras. Su puesta en cultivo se produjo 
décadas después de la conquista, ya a finales del siglo XII o inicios del XIII, a medida que se establecían nuevos colonos en la región y aumentaba la demanda de recursos. PALABRAS CLAVE: algezira; insula; riparia; arqueología agraria; al-Andalus; conquista feudal.

\section{ABSTRACT.}

The documentary and archaeological research conducted in the Lower Ebro Valley for the last decade has allowed us to study the riparian agrarian spaces that were associated with Andalusi rural settlements and Madīnat Țurțī̌sa. It has also enabled us to identify the transformations that were introduced by the feudal colonisation that followed the Christian occupation of the area in 1148. Mentions of algeziras or insulae are frequent in the written record generated by the conquerors. Both terms referred to riverbank areas that were totally or partially surrounded by rivers branches. These spaces were prone to flooding and subject to frequent changes but, at the same time, they were stable enough to spark settlers' interest in their exploitation and later colonisation. The Andalusi had not regularly cultivated these riparian environments. For them, their wild vegetation was the main resource to be utilised, primarily for pasture. After the conquest, feudal lords promoted the cultivation of cereals and vines and, especially, the ploughing of previously uncultivated areas. Among these were large sectors of the Ebro Delta, but also parts of its riverbanks, such as the algeziras. Their ploughing took place decades after the initial invasion, towards the late-twelfth and the early-thirteenth-centuries, as more settlers established themselves in the region and the demand for resources grew. KEYWORDS: algezira; insula; riparia; agrarian archaeology; Al-Andalus; feudal conquest.

\section{INTRODUCCIÓN}

Ramon Berenguer IV, príncipe de Aragón y conde de Barcelona, y sus aliados conquistaron las plazas de Tortosa y Lleida en 1148 y 1149 , respectivamente. Con el dominio de los principales centros urbanos el resto del territorio no tardó en caer bajo poder cristiano. Hacia 1153 culminaban las campañas militares con la toma de los grandes distritos de Miravet y Siurana. El repartimiento de los espacios urbanos y rurales y el proceso de colonización mediante el asentamiento de colonos cristianos generaron la redacción de centenares de documentos, en gran parte alienaciones de inmuebles. ${ }^{1}$ Estas contienen numerosas referencias a los componentes del espacio

1 Las referencias a los documentos procedentes de repertorios publicados se citan con el acrónimo correspondiente seguido del número del documento (DCT 1: 90; CTT: 45, por ejemplo). Los acrónimos, seguidos del autor o autores de la edición y el título figuran en la relación Siglas y fuentes primarias. Las referencias a la documentación inédita se citan en nota a pie de página. En los topónimos y antropónimos se ha mantenido el nombre en catalán. Por ejemplo, Santa Maria de Tortosa, en lugar de Santa María. 
agrario: cultivos, plantas, espacios incultos diversos, caminos y vías públicas, barrancos y torrentes, sistemas hidráulicos y molinos, núcleos de población, etc. Así mismo figuran constantes menciones a los ríos (el Segre y el Ebro) y sus orillas. La investigación llevada a cabo en los últimos 10 años en el bajo Ebro ha permitido, a partir de esta documentación y mediante recursos arqueológicos, estudiar los espacios agrarios de ribera vinculados a los asentamientos rurales andalusíes y a Madīnat Ṭurțūša, así como las transformaciones producidas en estos espacios por la colonización feudal tras la conquista. ${ }^{2}$ Hemos delimitado y descrito diversos espacios de cultivo en la llanura fluvial y su localización está estrechamente asociada a los lugares de residencia andalusí. Su disposición a lo largo de ambas riberas del Ebro es discontinua, dejando espacios incultos entre cada agrupación de parcelas. Se caracterizan por su situación habitualmente justo por encima de las cotas de inundación, preferentemente en las desembocaduras de los torrentes, donde se acumulan sedimentos. El procedimiento utilizado para la irrigación fue el de los pozos con noria. No existe ningún indicio ni documental ni arqueológico de un canal derivado del río Ebro. En algunas zonas (las Arenas y el prado de Tortosa, al sur de la ciudad, en el margen izquierdo del Ebro, y, en el margen derecho y enfrente de Tortosa) se documentan numerosas acequias de drenaje y espacios destinados principalmente al cereal (Puy, Balbo, Virgili y Kirchner, 2014; Kirchner, Virgili y Antolín, 2014; Kirchner i Virgili, 2018 y 2019; Virgili, 2019 y 2020; Virgili y Kirchner, 2019) (Figura 1).

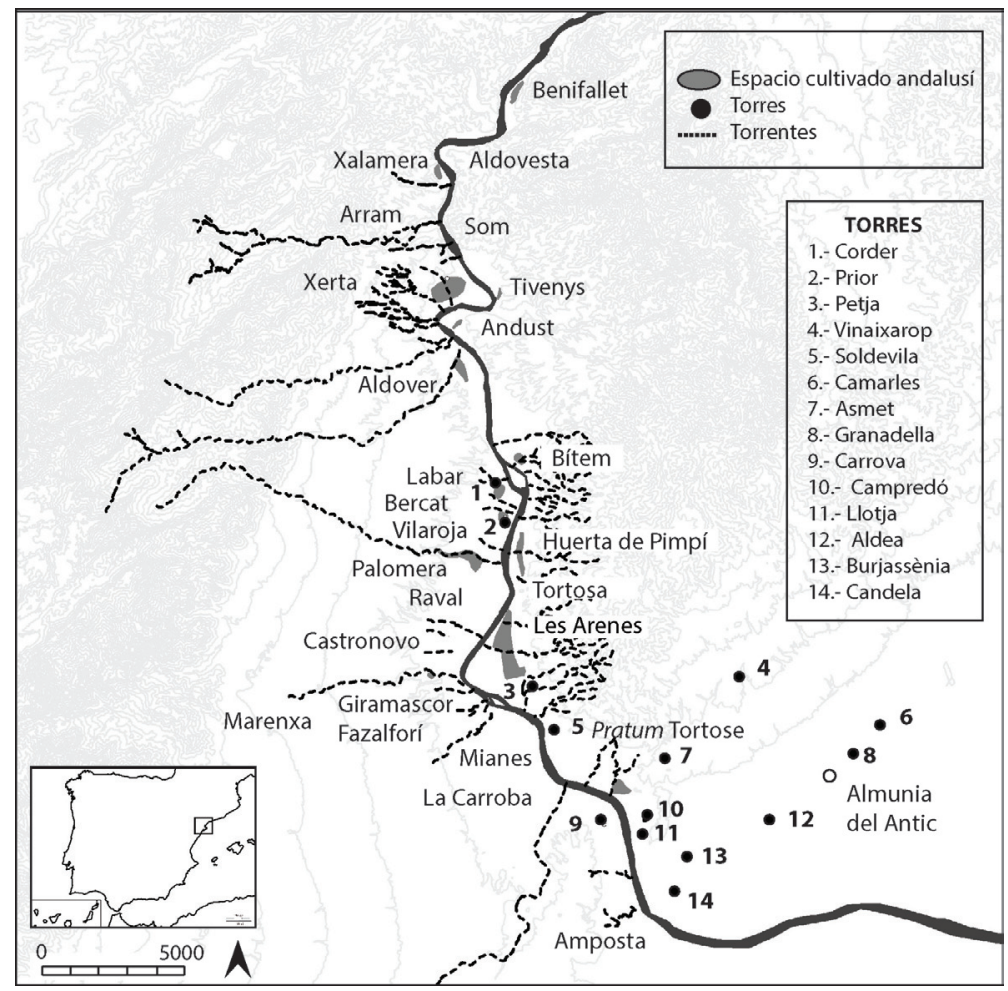

Figura 1: Asentamientos y espacios de cultivo en el bajo Ebre

2 La zona de investigación incluye el tramo del valle del Ebro de la comarca del Baix Ebre. 


\section{ALGEZIRAS, SOTOS, MEDIANAS Y GALACHOS}

En la documentación estudiada destacan las referencias a algeziras o insulae, según se utilice el término derivado del árabe (al-jazira) o el término latino, para referirse a unos espacios de ribera fluvial rodeados totalmente o parcialmente por brazos del río. El nombre popular y tradicional usado en las comarcas de la Ribera d'Ebre y Baix Ebre para designarlos es xiquina. ${ }^{3}$ Se trata de ámbitos de ribera fácilmente inundables y sujetos a modificaciones frecuentes aunque suficientemente estables como para suscitar el interés por su ocupación y explotación. Las avenidas o el flujo del río y de los torrentes tributarios podían arrancar o aportar sedimentos, así como cambiar sus contornos y las cotas de la superficie de estas islas fluviales. Estas suelen formarse en tramos de escaso gradiente, donde el curso del río tiende a trazar meandros y donde la deposición de sedimentos finos en el lecho fluvial se acentúa por la disminución de la velocidad de la escorrentía. Algunos márgenes rocosos pueden facilitar la acumulación de sedimentos y la formación de meandros o en la desembocadura de torrentes tributarios del río, donde también se acumulan los sedimentos aportados por éstos. Estos espacios de acumulación de sedimentos son los que reciben la denominación de islas en la documentación medieval.

Las islas fluviales las encontramos bien documentadas en el Ter, el Segre, el Llobregat y el Besós. También se encuentran abundantes menciones en el Ebro navarroaragonés y sus principales afluentes (Frago, 1979). Este tipo de espacio podía ser explotado como zona de pasto, con herbajes frescos todo el año, como suministro de materiales de construcción (arenas, cañas), o como áreas de cultivo, con plantaciones de lino, cáñamo, árboles frutales, hortalizas o viñas, a menudo con cultivo promiscuo. También se documentan molinos hidráulicos con sus canales y presas asociados a las islas (Martí, 1988). En el Ars Gramatica de Gisemundo, un tratado de agrimensura de finales del IX o principios del X, conocido por un manuscrito procedente de Santa Maria de Ripoll, se mencionan las insulae fluviales y cómo los cambios de curso de un río pueden hacerlas emerger (Martí, 1988; Toneatto, 1982).

Antes de que fuera posible la capacidad técnica para regular el caudal del Ebro o de construir azudes para derivar canales a finales del siglo XIX (Fabregat y Vidal, 2007; Vidal, 2010), el Ebro tenía un cauce mucho más amplio que en la actualidad, formado por diversos brazos de río que podían cambiar de curso fácilmente tras los periodos de crecida en primavera (deshielo de la nieve de las montañas) u otoño (lluvias torrenciales). Además de las islas fluviales, la documentación menciona sotos, medianas y lejas (sots i mitjanes en Catalunya), antiguos cauces y áreas inundables de ribera fluvial, delimitados a veces por una riba (o riber) que constituía el límite de lo que se puede considerar el cauce inundable del río, y solían ser espacios incultos (Monjo, 2012; Marfull, 2014; Lacámara, 2020). La documentación escrita

3 La xiquina se define como un brazo de tierra que penetra en el río (DCVB, 10, 948). 
alude, pues, a unos ámbitos de ribera fluvial, con un vocabulario diverso, como las insulae, algeziras, sotos y medianas, que pueden asociarse al concepto más genérico de riparia. Este concepto engloba diversas realidades de espacios ribereños, en este caso de tipo fluvial, en los que se desarrollaban relaciones de equilibrio entre el medio y las comunidades humanas que lo explotaban mediante distintos mecanismos de gestión del agua (Hermon 2014).

$\mathrm{Al}$ referirse a estas islas, los documentos mencionan a veces otro término: el alfalig (también, alhalig, alhalegium, alalix). Es una palabra de origen árabe (al-halij), que significa golfo, y que designaba el remanso de una corriente, un lugar de aguas tranquilas (Bramon, 2012, p. 17). Algunas de las islas documentadas en el Bajo Ebro tenían en sus límites un alfalig que separaba la isla de la tierra firme, cuyo origen era un antiguo brazo de río o un cauce seco en tiempos de estiaje. En algunos casos, parece que estos lechos secundarios fueron canalizados para estabilizar los límites de las islas y de los espacios de cultivo que contenían. En diversas localidades catalanas del valle del Ebro reciben el nombre de galarxos o galatxos, y en Aragón, galachos. El significado original de remanso es, pues, coherente con áreas de escaso gradiente que propician la formación de meandros. Los espacios comprendidos en los límites del meandro recibían el nombre de algezira o insula y podían tener un alfalig, brazo de río o canal que podía separar la isla de la orilla. Esta configuración del espacio de ribera con todos los componentes descritos (meandro pronunciado, isla fluvial, alfalig o galatxo) se encuentran, por ejemplo, en Xerta y en Miravet (Kirchner y Virgili, 2018, p. 29-33; Kirchner, Virgili, Rovira y Pica, 2020). El topónimo Flix, aguas arriba, probablemente alude también a un alfalig. Así mismo, son particularmente significativos los existentes en el curso medio del Ebro en torno a Zaragoza (Pellicer y Yetano, 1985; Pellicer, 2018; Najes, Ollero y Sánchez, 2019).

\section{TESTIMONIOS DOCUMENTALES DE LA INESTABILIDAD DE LOS ESPACIOS RIBEREÑOS}

En la documentación escrita medieval existen diversas referencias a la inestabilidad de los terrenos de las islas y a los conflictos de derechos que ello podía ocasionar. Uno de los preceptos de las "Costums de Tortosa", la compilación del derecho consuetudinario tortosino (1272), promulgadas en 1279, legisla con gran precisión sobre los efectos de las riadas con respecto a la propiedad de los depósitos de sedimentos y de las islas que puedan formarse en medio del río o en contacto con la orilla. ${ }^{4}$

4 Item, per alluvione. Item, per amagat creixement. Que si la força d'aygua a la honor d'alcú crex terra o la y aporta, aquel creximent o aquel aterra que axi y és aportada o lexada poc a poc, que hom no pot conéxer d'on s'i és venguda ne d'on és, és del señor d'aquela honor tot aquel creximent quant que sia. Però si arbres o ceps o plantes aquel alluvió en honor d'altre aportarà, són d'aquel e romanen de qui l'alluvió los pres, los ne pot portar e fer sa volentat. Mas si enans que el señor de qui foren, los prenga o.ls vula prendre, auran meses 
Además de los textos legales, se documentan casos concretos en previsión de los efectos de eventuales inundaciones reproduciendo las mismas condiciones. El 8 de marzo de 1268, Berenguer de Entença y su mujer Galbors, señores de la baronía de Entença, vendieron en alodio a la encomienda templaria de Miravet la insula llamada Algezira, en término de Tivissa y Miravet, con los árboles, la caza, la pesca y todos los derechos, por 500 morabetinos. El topónimo Algezira debía designar el lugar desde época andalusí. La transferencia se hacía con el consentimiento de los campesinos de Tivissa que trabajaban las parcelas, y se determinaba que éstos no pudiesen promover pleitos sobre los vasallos a los que la orden hubiera establecido. El documento refleja de manera fehaciente la inestabilidad de estos espacios a causa de los efectos de las crecidas del río, que podían modificar el lecho, inundar la isla, destruirla totalmente o en parte, provocar la pérdida de terreno (detrimentum) y, después, recuperar su estado inicial total o parcialmente. También se hace referencia a la posibilidad de que se acumulen sedimentos en toda la superficie o en una parte, que se partiera en dos o más sectores o que el lecho del río cambiara. El lecho antiguo sería ocupado por los señores eminentes, la orden del Temple, en compensación por los efectos de la creación de un nuevo cauce fluvial. Todas estas condiciones se enuncian para no perjudicar los intereses de la parte compradora en caso de avenidas suficientemente importantes como para que pudieran modificar los espacios de cultivo ribereños. ${ }^{5}$

rayls e.l loc on són venguts, són d'aquel de qui són los locs o nauran meses rayls. Ínsula, ço és, exequina que.s faça en mig de flum, és d'aquels que han les honors deçà e delà del flum, que.s tenen ab la riba del flum, ço és que cascú hi a frontera e guayna sa part en la ínsula, segons que ha frontera e.l flum de lonc en lonc del flum. Mas si la dita ínsula és pus prop de la una riba del flum que de l'altra, la sobredita ínsula és d'aquels de qui són les honors que són prop de la riba, e segons que cascú d'aquels hi han frontera en la riba del flum, deu aver part d'aquela ínsula o algezira o exsequina. Si la força de l'aygua del flum partex honor d'alcú, e la una part roman là on s'està, e l'altra en forma d'ínsula, o l'aygua.s muda, que partex la honor, ço és que roman part là on se era, e part que.s tén ab la terra que.l flum ha delenquida, tota via roman e és seynor d'aquela terra aquel qui abans n'era señor, e tot creximent que lo flum d'aquí enant faça a aquela honor e locs partits, atressí és seu. Item, si alguna ínsula té lo cap ab una de les honors que són en aquel loc, e no.s té ab neguna de les altres honors, per gran ne per longua ne per ampla que la dita ínsula sia, e tot lo creximent que fa ne farà, és d'aquel de qui és la honor ab qui té lo cap (Costums, Libre 9, rúbrica 21, costum 1, p. 475). Disposiciones similares son las que se registran en las Partidas de Alfonso X y en algunos fueros de la corona castellana (Bonachía 2012: p. 40-43; Del Val Valdivieso 2012: p. 81).

5 [...] dicta insula aliquo tempore per inundationem fluminis Iberi vel mutationem alvey vel aliqua alia rationem que dici vel excogitari possit occuparetur in totum vel in parte vel destrueretur vel in aliquo detrimentum pateretur, et postea r[ev]ertet insula vel alveus ad pristinum statum in totum vel in partem, quod tota sit vestra et sub vestro dominio consistat in perpetuum [...]. Item si per alluvionem aliquid adiciatur dicte insule ex quecumque parte vel alio quocumque modo, totum sit vestrum iure emptionis vestre. Et quamvis flumen Iberi per medium dividiretur et in medio esset insula vel divideret insula in duas partes vel plures, totum sit vestrum et non illorum qui prope ripam predia possiderent. Item si flumen naturalem alveum dereliquerit et alia parte fluere ceperit, totus alveus consuetus dicte insule sit vester et sub hac venditione consistat. Archivo Histórico Nacional, Madrid (desde ahora AHN). Órdenes Militares, San Juan de Jerusalén, Castellanía de Amposta, Miravet, carp. 609, perg. 45; Arxiu de la Corona d'Aragó (desde ahora, ACA). Registro 15, f. 47v-48r. 
Otro documento, fechado el 18 de julio de 1318, referido a un establecimiento sobre una 'parellada' situada delante mismo de Miravet, adyacente a la ribera fluvial, hace referencia al sedimento que el río podría añadir a esta parcela, haciendo constar que la totalidad de los derechos serían para la señoría y no para el campesino. ${ }^{6} \mathrm{El}$ detalle con el que se explican todas las posibilidades que podían afectar los espacios adyacentes al lecho fluvial demuestra que estos fenómenos eran habituales en las riberas del Ebro y que sus consecuencias eran bien conocidas.

El 5 de junio de 1383, Miquel Cirera, prior de la iglesia de Tortosa, reconocía a Pere Mascarell, ciudadano de Tortosa, que Joan de Naters, jurispérito, también ciudadano de Tortosa, había dado al prior y al priorato dos jornales y medio de tierra campa que ya tenía para él en enfiteusis, a censo de quince sueldos a pagar por San Miguel, en el término de Tortosa, en Pimpí, cerca de "las eras de Vimpeçol". La donación estuvo motivada por una crecida del Ebro y la consecuente inundación que provocó que aquella pieza de tierra prácticamente desapareciera. El prior daba lo que quedaba de la pieza a Pere Mascarell para que la trabajara, sin ningún censo. Sin embargo, si a causa de una nueva crecida del río, los dos jornales y medio de tierra volvían a su estado inicial, el receptor debía entregar quince sueldos de Barcelona al año por San Miguel en concepto de censo. ${ }^{7}$

Justamente, para prevenir los estragos de las inundaciones sobre la ribera, en el año 1416, las dignidades hospitalarias ordenaron construir una peixera en el Ebro, para evitar la entrada de agua en una pieza de tierra del término de Miravet, llamada Illa, que los frailes concedieron a la aljama del lugar, a condición de roturarla y ponerla en cultivo ya que estaba llena de maleza, inculta e infructífera. Se trataba de una franja de tierra lindante con el río, tal como se indica en uno de sus límites. ${ }^{8} \mathrm{La}$ peixera era un muro de contención construido en la ribera para evitar la desviación del río o las inundaciones. El muro consistía en una serie de postes clavados en el suelo que servían de soporte a unas tablas colocadas horizontalmente con la finalidad de contener la corriente fluvial y evitar la entrada del agua en las parcelas de la orilla (DCVB, 8, p. 386). La construcción de otra peixera está también documentada en el sector de Giramascor, cerca del camino de València, en la orilla derecha del Ebro, al sur de la ciudad de Tortosa (Vidal, 2008, p. 186). Así mismo, las Costums preveían levantar diques (peixeres) con la finalidad de proteger las tierras de cultivo, siempre y cuando no obstaculizaran la navegación fluvial. ${ }^{9}$

6 Et si forte predictum flumine ubi a ripibus que modo sunt usque in aquam aliquod riber seu ribers dimiserit, totum illud quantum sit penes nos retinemus et successores nostros. AHN. Órdenes Militares, San Juan de Jerusalén, Castellanía de Amposta. Miravet, carpeta 610, perg. 94.

7 ACT. Cajón 53. Tevizola, Anglerola, Bítem, legajo 3, perg. s. n.

8 AHN. Órdenes Militares, San Juan de Jerusalén, Castellanía de Amposta. Miravet, carpeta 614, perg. 165.

9 E poden fer pexeres e.ls flums e e.ls torrents a defensió de lurs honors (Costums, Llibre 1, rúbrica 2, costum 4, p. 18). 
La documentación posterior, de época moderna, deja constancia de que los cambios morfológicos en el cauce del río y la ribera fluvial eran un fenómeno habitual y recurrente a lo largo de los siglos. Un documento del año 1606, hace constar que si el río se lleva la tierra de una heredad y luego la restituye, la tierra depositada pertenecerá al señor. ${ }^{10}$

También en la llanura deltaica, como depositaria de la mayor parte de los sedimentos arrastrados por el río y, a la vez, por ser un espacio con marjales y lagunas abundantes, se producían transformaciones importantes. La documentación medieval alude a estas características a menudo (Virgili, Mateu y Pacheco, 2020). Los efectos de la erosión y la sedimentación provocados por las avenidas están también evidenciados en la cartografía de época moderna (siglos XVII y XVIII) custodiada en los archivos de Tortosa. Los textos que acompañan los planos hacen referencia a la formación de islas o a su desaparición: "esta illa se l'enporta lo riu després de 1700"; "illa, y ia no la roda lo riu, antes sí"; "Esta illa se va doent lo riu en la part de Carlet 1720"; "illa que ia no és, pues ia no la roda lo riu". ${ }^{11}$

\section{LOS RECURSOS DE LOS ESPACIOS DE RIBERA}

Parece que en época andalusí estos espacios ribereños, tanto los sotos como las islas, habían sido aprovechados mayoritariamente como áreas de caza, recolección y pasto, donde obtener recursos forestales, sosa, sal y materiales de construcción (arena y cañas) y eran de acceso libre. Estas actividades habrían tenido una escasa incidencia transformadora sobre el medio. El aprovechamiento de estos espacios incultos, entre los que figuran los humedales, cuestiona la visión negativa de unos ecosistemas aparentemente hostiles al desarrollo de la vida humana. Sin embargo, los espacios ribereños también podían ser en parte cultivados, ya que se mencionan árboles y parcelas en cultivo desde fechas simultáneas o cercanas a la conquista cristiana, como en Xerta (Kirchner y Virgili, 2018; Virgili y Kirchner, 2019), en los alrededores de Zaragoza (Lacámara 2020) y en otros lugares a los que haremos referencia en este estudio.

Tras la conquista, los señores feudales adaptaron el paisaje rural según nuevos intereses, lo que se tradujo en otras formas de gestionar los recursos y transformaciones profundas en los espacios de cultivo. Entre otras acciones, pusieron en marcha

10 “... de tot en tot se'n portarà alguna heretat que no reste res de aquella e après torna dit riu a leixar terra en lo lloch on estava la tal heretat, la dita terra leixada es en tot y per tot de dit senyor castellà"; y añade que las islas que se formen en el Ebro pertenecerán al señor sin que nadie pueda reclamar derechos sobre ellas: "les illes que's fan y naixen, que's faran y naixeran en lo dit riu Ebro dins lo dit terme són totes y se esguarden a dit senyor (..) y a líbera diposició de aquell, sense que cap terratinent veí hi pugui reclamar dret algún". AHN. OOMM, San Juan de Jerusalén, Castellanía de Amposta, libro 1849.

11 Arxiu Comarcal del Baix Ebre (desde ahora, ACBE). Sección Cartográfica. Arxiu Capitular de la Catedral de Tortosa (desde ahora ACT). Cajón 45, Rectoria de l'Aldea. 
programas de colonización agraria de sectores hasta entonces incultos, ampliando el área cultivada. ${ }^{12}$ Este proceso afectó, sobre todo, los terrenos adyacentes a las orillas fluviales y las zonas de prado y marjal, al sur de Tortosa, en los tramos más cercanos a la desembocadura del Ebro. Las zonas húmedas del curso bajo del Ebro, entre Tortosa y la desembocadura, son denominadas en los documentos como pratum (prado). Los colonizadores tenían ante sí grandes extensiones de terreno que podían convertir en tierra de labor, previo acondicionamiento de los marjales y las ínsulas fluviales (Virgili, 2019 y 2020). El proceso afectó poderosamente al medio y supuso la sustitución parcial de unos aprovechamientos ancestrales de caza, recolección y pastos para la ganadería, por cultivos especulativos de viña, cereal y frutales, según los intereses de la oligarquía dirigente. A pesar de las dinámicas de colonización agraria a partir de la conquista cristiana, la actividad ganadera se intensificó, como pone de manifiesto el interés señorial por el monopolio y el control de los pastos (Fabregat, 2006: p. 151-158; Royo, 2020; Virgili, 2020).

\section{LAS ALGEZIRAS DEL BAJO EBRO}

La documentación de los siglos XII y XIII menciona varias algeziras en ambas orillas del Ebro. Desde Benifallet, el asentamiento más septentrional, hasta el distrito del Castillo de Amposta, bajo señoría de la orden del Hospital, en la ribera derecha, y hasta la desembocadura en el lóbulo izquierdo del delta. Benifallet es el único asentamiento cuyo término abraza uno y otro lado del Ebro.

\subsection{Las algeziras de Benifallet}

En Benifallet se documentan varias algeziras o ínsulas. En 1167, Alegret de Altafulla y su mujer Berenguera confirmaban la división de la algezira de Benifallet que compartían con el obispo de Tortosa y el cabildo (DCT 1: 170). Unos años después, en 1173, Alegret hacía donación de su parte de esta insula que est ante Benifelet a la mitra y los canónigos (DCT 1: 248). Limitaba al este con el alodio del obispo y el cabildo, y con el Ebro por el resto de lados. Consta que el donador tenía la isla por donación condal, con la tierra y los árboles existentes. Se refiere, sin ninguna duda, al mismo espacio. La localización de la isla delante de Benifallet indica que estaba a la altura de este lugar. Según los límites consignados en el segundo de los documentos se desprende que podría estar a la izquierda del Ebro, puesto que limita con

12 Estos procesos de creación de nuevos espacios de cultivo a costa de sectores incultos son característicos de las zonas de conquista y colonización como, por ejemplo, en el Reino de Valencia (Torró, 2010, 2016 y 2019). David Lacámara documenta acciones de roturación agraria y actividades extractivas e industriales en ámbitos de ribera fluvial en los alrededores de Zaragoza desde fines de la Edad Media y sitúa en este instante el inicio de la degradación del entorno natural a raíz de la intervención humana (Lacámara, 2020). 
el río a poniente. En la actualidad existe la llamada isla de Benifallet, justo delante de la población, pero queda pegada a la orilla derecha y separada de esta por un estrecho brazo de río, un galacho, el Galatxo de Benifallet, tal como es conocido hoy en día. La localización actual, pues, no permite identificar esta isla y galacho con la isla medieval, aunque sí que indica que este tramo de río favorece la formación de este tipo de acumulación de sedimentos.

En los primeros momentos después de la conquista consta otra algezira conocida como Astet, o Anastet, un topónimo que se ha conservado y designa una partida situada en el norte del municipio, a la izquierda del Ebro, limítrofe con Rasquera y Miravet, en un pronunciado meandro. En octubre del año 1154, Ramón Berenguer IV, entre otros bienes, entregaba a la iglesia de Santa María de Tortosa y al obispo Gaufred todo lo que tenía en Anastet (DCT 1: 47). Tres meses después, el conde confirmaba la donación (DCT 1: 52), y el año siguiente, lo hacía el papa Adriano IV (DCT 1: 64). Pocos años después, en julio de 1158, Pere Forbidor y su mujer Ricsenda dieron a la iglesia y al obispo los derechos que tenían en Anasteth (DCT 1: 91). Hay que esperar a abril de 1199 para caracterizar y situar este paraje, cuando el obispo y el prior de Tortosa dieron a los hermanos Bernat y Arnau Pinyol la algezira Anastet, que estaba en el lugar de Benifallet, término de Tortosa, a censo de 14 cántaros de aceite, con la condición de trabajarla y plantarla, y no enajenarla durante los siguientes veinte años (DCT 2: 586). Esta algezira se puede localizar gracias a la pervivencia del topónimo -camino de Astet- que sigue paralelo al río y en el lado interior del paquete de sedimentación completamente llano de casi 80ha de superficie, situado entre la sierra, al este, y el Ebro, a poniente. No está en la desembocadura de ningún torrente, por lo que parece el resultado de un proceso de acumulación de sedimentos generado por el propio río justo detrás del relieve abrupto que sobresale en el margen izquierdo (Figura 2).

En 1227, el obispo y el cabildo establecían a un grupo de sarracenos de Benifallet -parecen los representantes de la aljama del lugar, puesto que se mencionan el alcaide y el alamín- sobre una pieza de tierra situada en el lugar de la Cova de la vall del Cavall (DCT 3: 879). Limitaba al sur con el Ebro, a levante con una algezira y a poniente con la montaña. Esta algezira consta tan solo en los límites, pero parece que cabe situarla claramente en la orilla derecha.

En el límite meridional del término de Benifallet, en la orilla derecha del río, se localiza el manso de la Xalamera, justo donde el barranco del mismo nombre vierte sus aguas al Ebro. El edificio y las tierras de cultivo adyacentes se encuentran en la acumulación sedimentaria formada por la desembocadura de este torrente; tal vez por ello, el primer documento que menciona Xalamera califica este espacio de algezira. En efecto, en junio de 1157, el conde Ramon Berenguer IV hizo donación a la orden del Hospital, en mano del maestre de Amposta, de ipsam algediram de Xalamera, en heredad propia y franca, y Guillem Ramon de Montcada renunciaba a 


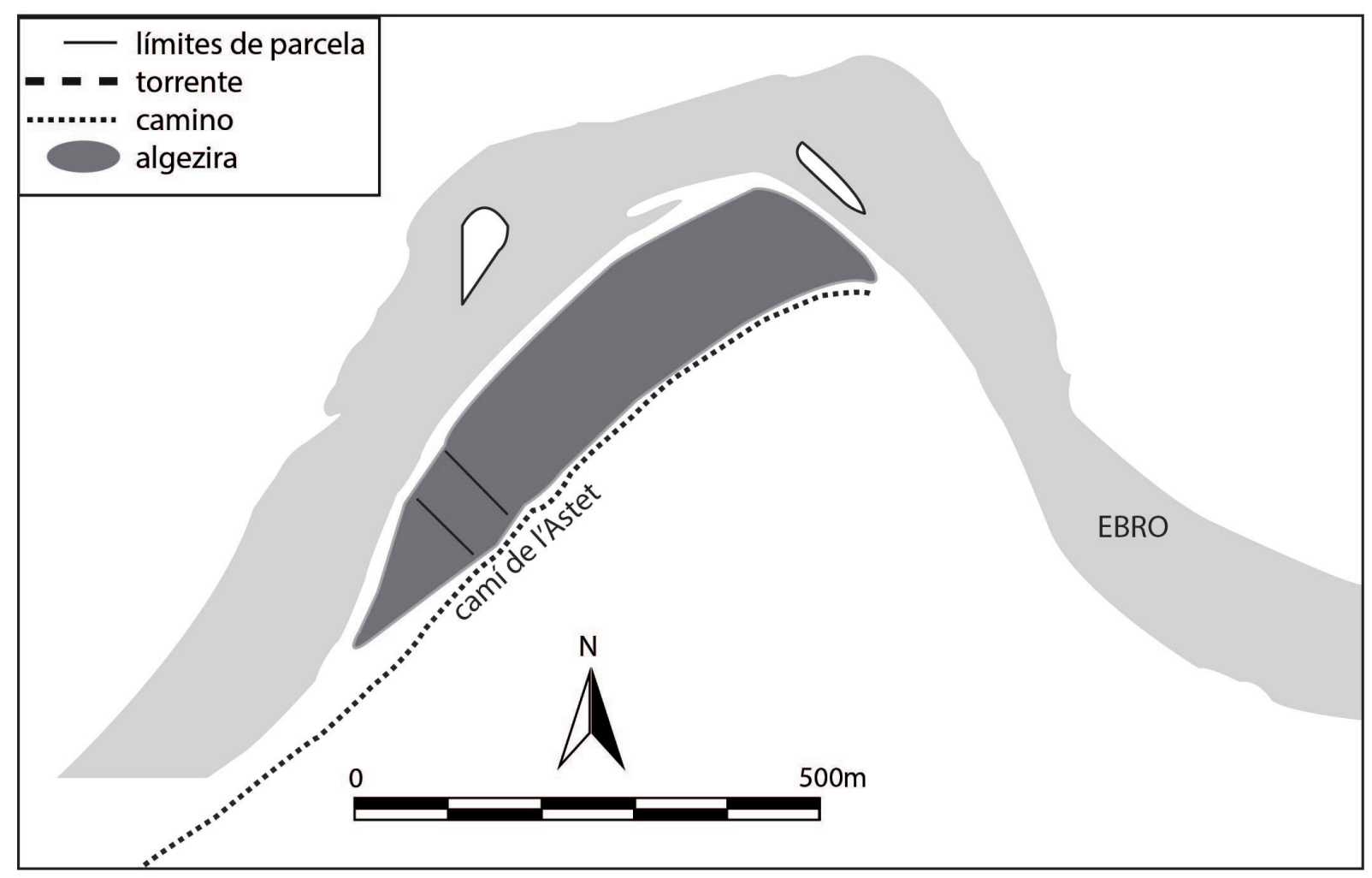

Figura 2: La algezira de Anastet (Benifallet)



Figura 3: La algezira de Xalamera (Benifallet) 
los derechos que le correspondían por acción de conquista favor de la orden (DCT 3: 1334 (80 bis)). El parcelario de la ínsula ha sido intensamente modificado por obras de concentración parcelaria y la plantación de cítricos. Cerca de la masía de Xalamera se conservan restos de un pozo con noria de tracción animal. Las norias eran los procedimientos característicos de regadío de los espacios de cultivo de origen andalusí en las orillas fluviales del Bajo Ebro, por lo que se podría pensar en un origen andalusí de esta estructura hidráulica. La prospección del lugar permitió localizar restos de una acequia y del azud que recogía el agua del barranco de Xalamera. La acequia salvaba un torrente lateral a través de un espectacular acueducto conocido como los Arquets de Xalamera, cuya factura arquitectónica parece ser bajomedieval. Así mismo, en el edificio de la masía se conservan arcos de diafragma típicamente bajomedievales y en un extremo se observan contrafuertes que parecen evidenciar los restos de una torre de planta cuadrangular (Figura 3).

\subsection{Las algeziras de la orilla derecha}

\section{a) Las algeziras de Xerta}

En el límite septentrional del actual término municipal de Xerta se encuentra la masía del Arram y un espacio de cultivo adyacente, situado en la desembocadura del barranco del mismo nombre.

De este asentamiento se conserva muy poca documentación escrita. En una relación de bienes de la mezquita de Xerta se mencionan unas piezas de tierra en Abdalaram y también en Azaned, iuxta viam que vadit ad Pauls (DCT 1: 495). En una lista de bienes del monasterio de Poblet constan unas piezas de tierra en Assanet, en el lugar de Alaran (o Alairan) (CP: 185). Parece claro que ambos topónimos están estrechamente relacionados. En 1196, hay un reconocimiento de los derechos que Poblet tenía en el castello Alaran, en el que había un campo y una algezira con una cueva, al lado de una vía pública, con un canal a mediodía y con la montaña de dicho castillo a levante (CP: 186). Esta mención, pues, sitúa una algezira en el mismo lugar. La "montaña del castillo" sería el promontorio situado en el lado derecho de la desembocadura del torrente y en la orilla del río Ebro, donde se ha encontrado cerámica andalusí en superficie y restos de muros. Ello permite localizar el campo y la algezira al oeste del promontorio, en el espacio agrario de fondo de valle, acondicionado en los sedimentos aportados por el barranco del Arram y conocido como Caldera de l'Arram. Este espacio podría haber sido regado por dos norias hoy desaparecidas (Figura 4).

En Xerta, la mayoría de las parcelas cultivadas documentadas tras la conquista constituyen un parcelario compacto, sin apenas contacto con la orilla fluvial, si nos atenemos a la ausencia de lindes con el Ebro. Es probable, por tanto, que este parce- 


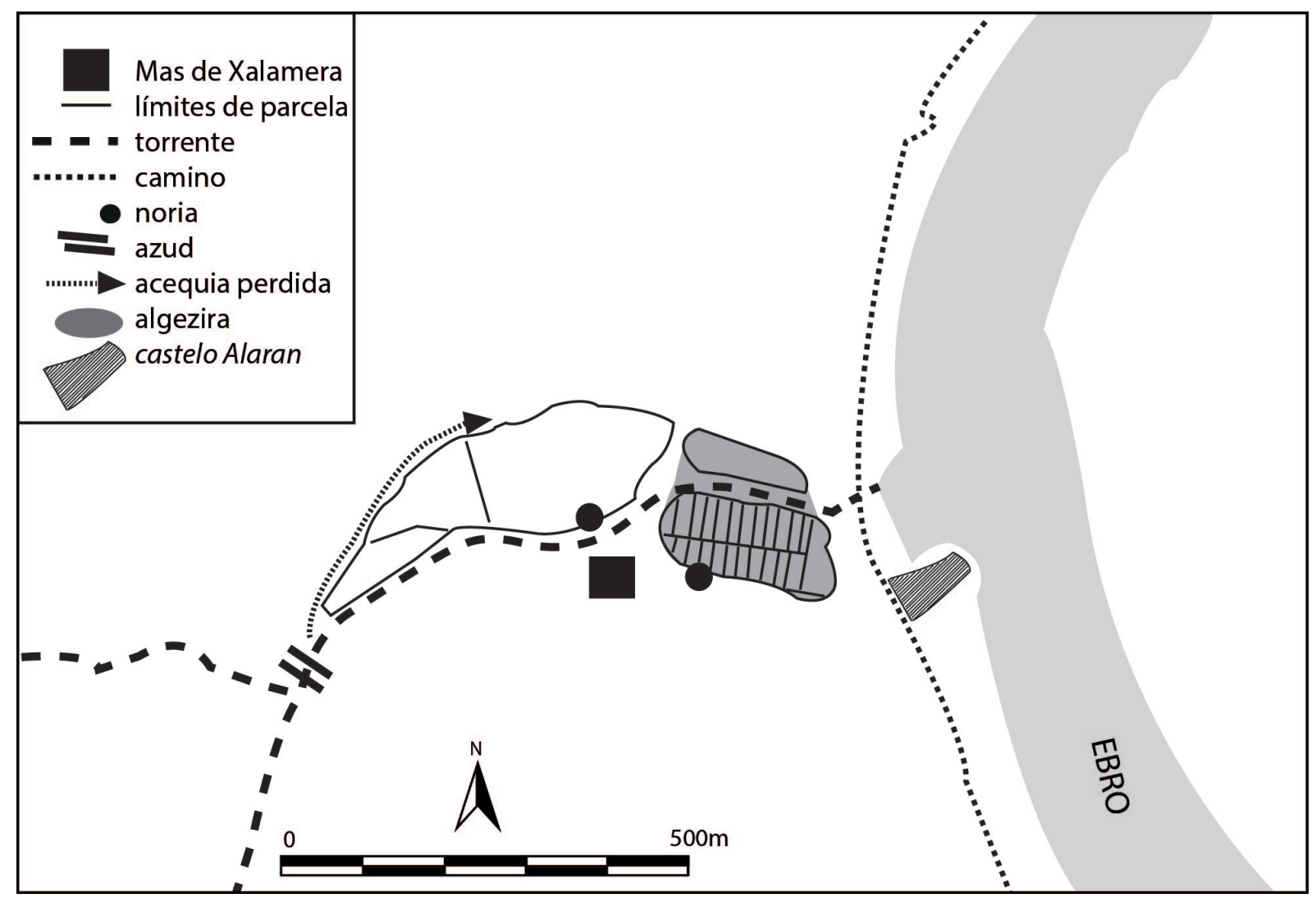

Figura 4: La algezira del Arram (Xerta)



Figura 5: La algezira de Xerta 
lario se correspondiera, a grandes rasgos, con el antiguo espacio de cultivo andalusí, regado mediante pozos y norias (Kirchner y Virgili, 2018; Virgili y Kirchner, 2019) (Figura 5-C, D).

La primera mención a la algezira de Xerta consta en un documento del año 1167, en una venta al prior del cabildo de Tortosa de la cuarta parte de los derechos sobre una algezira situada inter duas aquas inter Exerta et Tivenix (DCT 1: 174). Poco después tenía lugar una nueva venta al prior de la cuarta parte de una algezira que est inter ambas aquas ante Tivenx (DCT 1: 177). En ambos casos, los vendedores manifiestan que tenían sus respectivas porciones por concesión de Ramon Berenguer IV, y constan los antiguos poseedores andalusíes, calificados de exaricos. No existe ningún indicio de un eventual cultivo en este espacio.

Todo parece indicar que esta algezira no fue objeto de cultivo generalizado antes de la conquista. A pesar de su temprana posesión por la sede de Tortosa, no se observan los primeros impulsos de colonización hasta inicios del siglo XIII, en fechas alejadas de la conquista, por iniciativa del obispo y el prior. En la década que transcurre entre 1205 y 1216 se formalizaron seis establecimientos sobre parcelas situadas en esta algezira que, además, limitaba con un alfalig. ${ }^{13}$ Una de las condiciones impuestas a los censatarios era roturar las tierras incultas y plantar, circunstancia que debe relacionarse con los nuevos procesos de colonización agraria en estos espacios adyacentes a la orilla. Sin embargo, se advierte la presencia de otros poseedores, además de los receptores de los contratos, los cuales figuran en los lindes de las parcelas que probablemente se habían puesto en cultivo con anterioridad.

No resulta fácil la reconstrucción del espacio que ocupan el alfalig y la algezira de Xerta a partir de los documentos, ya que desconocemos como era entonces el cauce del Ebro en aquel lugar. No obstante, se pueden observar algunas agrupaciones parcelarias y diferencias microtopográficas en la fotografía aérea y los mapas topográficos, respectivamente, y que se han plasmado en la reconstrucción planimétrica. En primer lugar, el alfalig y la algezira eran contiguos puesto que en dos ocasiones el primero figura al norte y la segunda a poniente. El alfalig de Xerta siempre linda con la algezira y también con otras parcelas u honores (DCT: 649, 652). Las distintas piezas de la algezira lindaban con el Ebro, ya al norte, al este o al sur. Estas informaciones parecen situar esos espacios, el alfalig y la algezira, en el gran meandro que el Ebro traza delante de Xerta, y que actualmente constituye la parte más extensa de la huerta. El hecho de que el río figure al oeste en dos ocasiones, tanto del alfalig como de la parte sur de la algezira, sugiere que podía ser mucho más cerrado por los extremos que en la actualidad.

En el meandro de Xerta, en su extremo norte, existe un Mas del Galatxo en una partida rural llamada Les Illes. A la misma zona llega un camino procedente de Xer-

13 DCT 2: 649, 652, 653 y 698; DCT 3: 777 y 831. 
ta llamado Camí de les Illes que en su tramo final se divide en tres. Uno de ellos se dirige hacia el Mas del Galatxo. Este camino y sus brazales transcurren por encima de la cota de $12 \mathrm{msm}$ y delimitan la actual partida de las Illes. Este sería el espacio donde se produjo esta operación de colonización agrícola dirigida por la sede de Tortosa (Figura 5-B).

\section{b) Algeziras en Palomera y Caborrec}

Alrededor del actual barrio de Jesús (Tortosa) se extiende la partida rural llamada Molins del Comte, en alusión al área de molienda que concedieron los condes de Barcelona a la sede de Tortosa (Kirchner, en prensa). En la documentación medieval se hace constar que los molinos estaban en Palomera, un topónimo que designa todo el área del curso bajo del barranco de la Vall Cervera, que desemboca en el Ebro. En 1190, la encomienda del Temple de Tortosa compró un campo en Palomera, el cual limitaba a levante con el alfalig (galatxo) y con una algezira (CTT: 97); en el resto de lados del campo había posesiones de la propia orden, con lo cual, ésta completaba el dominio territorial de este sector. No hay duda, pues, de la existencia de una ínsula separada de la orilla por un brazo de río, el alfalig (o galacho). Esta algezira es difícil de identificar en el parcelario actual, aunque podría estar situada en la zona de la desembocadura del torrente de Cervera (Figura 6).

En la documentación inmediata a la conquista consta un topónimo, Caborrec, que parece designar el arranque de una acequia, que no ha podido ser localizado, aunque podría ser contiguo al sector de Palomera. ${ }^{14}$ En 1192, Vicenç, hospitalario del cabildo de Tortosa formalizaba un establecimiento sobre una algezira en Caborrec que limitaba a levante con una acequia y en el resto de puntos con piezas calificadas de honores, sin especificar los cultivos (DCT 1: 479). De esta algezira se dice que había tierra cultivada y yerma con distintos árboles. El receptor tenía que poner la tierra en cultivo y podar los árboles, a censo de una cuarta parte de la cosecha. La condición de cultivar y la demanda de una renta tan onerosa parecen indicar la inminente puesta en cultivo de una explotación de la que se esperaban rendimientos seguros. La algezira no limitaba con el Ebro, por lo que probablemente, la acumulación de sedimentos y cambios del cauce fluvial habían provocado su integración en la ribera.

14 En el Archivo Capitular de la Catedral de Tortosa, el cajón 59 alberga los pergaminos de Molins del Comte, Palomera, Caborrec y Castellnou. Caborrec es el único sin identificar, pero a partir de esta referencia se puede sugerir un emplazamiento adyacente o cercano a los anteriores. 


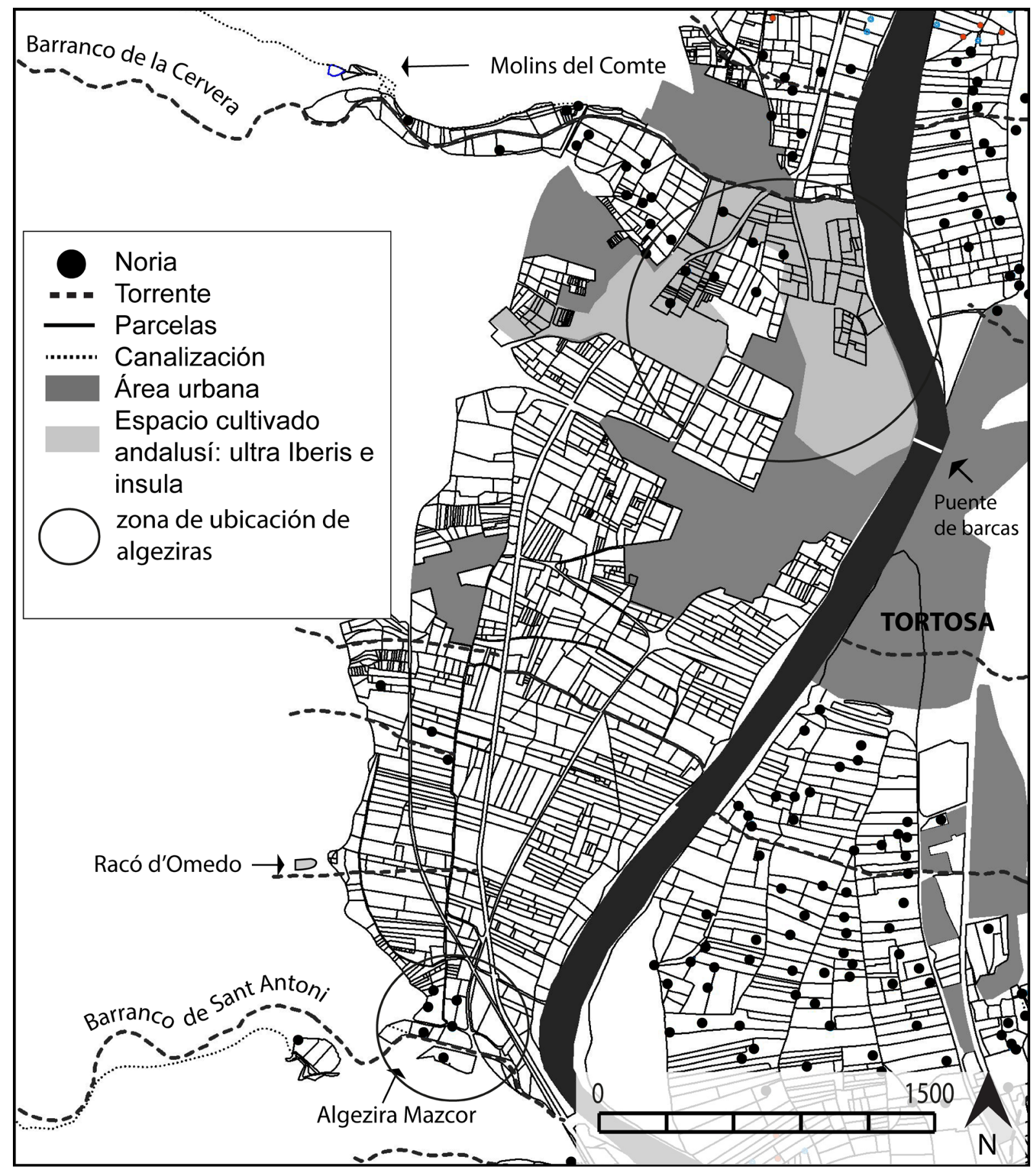

Figura 6: La zona de ultra Iberis (algeziras de Palomera, Caborrec, insula Iberis) y la Algezira Mascor y su entorno.

c) La insula Iberis

En noviembre de 1148, en pleno asedio de Tortosa, Ramon Berenguer IV concedió dos tercios de la insula Iberis (isla del Ebro) a la iglesia episcopal de San Lorenzo de Génova. ${ }^{15}$ El tercio restante correspondía al Común de la misma ciudad, en virtud de

15 CDRG, I: 190. 
los pactos de repartimiento firmados con el conde de Barcelona. En enero de 1151, el Común de Génova hizo entrega de su porción a la sede genovesa, por lo que el cabildo de San Lorenzo pasó a ejercer el dominio completo de este sector. ${ }^{16}$ Una de las cláusulas de la cesión era no poner obstáculos a una eventual construcción de un puente que enlazara ambas orillas y que se pudiera fijar en la ribera de la isla. ${ }^{17}$ Esta disposición demuestra que la insula Iberis estaba ya unida a la orilla derecha; si no fuera así no tendría sentido instalar allí la cabeza de puente. En el último tercio del siglo XIII consta la existencia de un puente de barcas que unía ambas riberas (Curto, 1993, p. 17-43).

Los documentos de la segunda mitad del siglo XII identifican este sector con dos denominaciones: ultra Iberis (más allá del Ebro) y Arrabal (también Arrabat, Rabat, o Ravat), los cuales comprendían el área central de la margen derecha del Ebro, justo enfrente de la ciudad, y corresponden a la insula Iberis. La expresión ultra Iberis se ha de entender desde la perspectiva de Tortosa, ya que se refiere a la orilla opuesta respecto de la ciudad. El 19 de abril de 1289, el cabildo de San Lorenzo vendió la insula que sita est ante civitate Tortose in flumine Iberi a Arnau de Jardí, obispo de Tortosa. ${ }^{18}$ Este documento y una memoria correspondiente al año 1705 , la cual recoge escrituras de fechas anteriores, permiten identificar, sin ninguna duda, la insula Iberis con la zona de ultra Iberis y el topónimo de Arrabal ${ }^{19}$. Uno de los asentamientos de la memoria hace referencia a un campo cerca del puente de barcas, en el arrabal, vulgarmente conocido como el Campo de la Parellada y antiguamente Isla de San Lorenzo. Dice también que, según la tradición, un gran brazo de río rodeaba esta área generando lagunas y charcas. A tenor de lo dicho, se trataría de un cauce seco que recuperaría la corriente en caso de riadas y desbordamientos ocasionales. En la actualidad, este sector está urbanizado en su totalidad, y corresponde al barrio de Ferreries, antiguamente conocido con el nombre de "dellà lo pont" (Miravall, 1998), y también, como hemos dicho, la Parellada, la insula Iberis o Isla de los Genoveses. Sin embargo, las cotas indican la existencia de áreas ligeramente sobre elevadas respecto al espacio circundante de la ribera que bien podrían fosilizar las antiguas islas (Figura 6).

A raíz de la conquista, este sector fue objeto de un repartimiento intensivo. La mayor parte de los receptores eran genoveses, lo que concuerda con el dominio eminente del común y de la Iglesia de Génova ${ }^{20}$. Esta información revela, a su vez, que todo este sector constituía un espacio agrario en el momento de la conquista

\footnotetext{
16 CDRG: 203 y DCT: 25.

17 (...) si in predicto flumine pontem aut molendinos fieri contigerit prephata ecclesia vel aliquis per eam prohibere non possit, quin pons in ripa insula firmetur (CDRG, I: 190).

18 ACT. Cajón 56, Génova, Vila-roja, perg. 8/48.

19 ACT. Cajón 59, Pescatería, legajo 75: escrituras y establecimientos de la Parellada.

20 ACA. Órdenes Militares, Gran Priorat, Tortosa, Códice 115, d. 14, f. 5v; CTT: 21, 25, 27, 28, 40, 41.
} 
cristiana, puesto que los documentos mencionan acequias, pozos, norias y albercas (DCT 1: 368; CTT: 27 y 29).

La Encomienda del Temple de Tortosa acumuló un importante patrimonio en este sector tras la compra de muchos inmuebles; la mayoría de ellos limitaban con otras parcelas de su propiedad, ${ }^{21}$ en torno de un núcleo que los documentos mencionan como almunia, parellada, manso, y también torre..$^{22}$ Además, el sector descrito estaba situado en parte en la orilla del Ebro, puesto que el río consta a levante de distintas parcelas. ${ }^{23}$ La cercana presencia del Ebro, así como la existencia de un cruce de caminos sugieren que la zona se encontraba enfrente de la ciudad de Tortosa, donde se asentará la cabeza del puente de barcas a finales del siglo XIII. Al tratarse de un sector muy urbanizado, entre los barrios de Tortosa y la villa de Roquetes, núcleo muy cercano, un poco al interior, y el hecho de encontrarse en los límites de inundación no permite reproducir el parcelario que reflejan los documentos. En este sector, las curvas de nivel ponen de relieve que la cota alrededor de la cabeza de puente era ligeramente más elevada que los terrenos adyacentes. Esta cota sería el resultado de las aportaciones de sedimentos del barranco de la Cervera (Figura 6).

Los inmuebles documentados son calificados de terra o campus, sin mencionar en ningún caso cultivos específicos: viñas, huertos u olivares, habituales en los otros espacios de cultivo del bajo Ebre. A tenor de estas calificaciones el espacio se destinaría de forma preferente al cultivo de cereales, pero también podía designar terrenos de prado, inundables, susceptibles de ser cultivados o aprovechar los pastos. Las acequias podrían referirse a una misma canalización, cuya finalidad sería el drenaje y en ningún caso el regadío, puesto que nunca se relacionan con huertos. Las acequias de drenaje eran necesarias para evacuar las aguas acumuladas por los desbordamientos del río o las aportaciones de los barrancos. Los espacios destinados a huerto, situados en algún lugar de las parcelas alienadas, como el de Raval (o Arrabal), serían regados con el agua de los pozos elevada mediante norias, según revelan los pozos y las albercas documentadas. ${ }^{24}$ Ese sector tenía su continuidad hacia el sur, en Castellnou, que la documentación revela como un gran espacio de aguazales equipado con una red de acequias de drenaje, pero no menciona ninguna algezira (Figura 6).

\section{d) Algezira Mascor y su entorno}

Los documentos de los siglos XII y XIII mencionan los topónimos Algezira Mascor, o Mazcor, (luego Giramascor), Alcántara, Beniguerau y Quarto (o Quart). A pesar de no haberse conservado en la actualidad, la información de los textos permite si-

21 CTT: 17, 20, 21, 25, etc.

22 Almunia (CTT: 27, 30 y 31); parellada (CTT: 38); manso (CTT: 29); torre (DCT 1: 341; CTT: 77).

23 CTT: 21, 31, 34 y 41.

24 ACA. Órdenes Militares, Gran Priorat, Tortosa, Códice 115, d. 3, f. 2v. 
tuarlos en torno a la desembocadura del barranco de Sant Antoni, en la confluencia de los actuales términos municipales de Tortosa y Roquetes, y que los cuatro eran adyacentes. La llanura fluvial situada entre el camino y el cauce actual era una zona de aguazales con la presencia de brazos de río que rodeaban franjas de terreno inestables y constituía una extensa área de prado.

La isla a la que hace referencia el topónimo Algezira Mascor podría estar situada en este sector, como muestra una donación a favor de los templarios de una algezira rodeada por el Ebro al norte, este y sur, y adherida a poniente con la Algezira Mascor, nombre que designaría el lugar en su conjunto (CTT: 126). En el punto de intersección con la vía de Valencia había un campo con un pozo y una alberca (puteo et zafareg), junto a la algezira que había pertenecido a Zahada, y al puente seco (pontem siccum) (DCT 1: 63). Otra pieza de tierra en Algezira Mascor estaba prope ipsam Alcantaram (puente, en árabe) (DCT 1: 69). En este sector había un lugar llamado Quart (o Quarto), como atestigua la existencia de un campo situado en Alcántara de Quarto, que limitaba al norte con la vía de Valencia y a levante con el camino del castrum de Amposta (DSC: 79); consta también un campo de la Sede de Tortosa situado in ipsa planicie ante castrum de Quart (DCT 1: 54 y 81). En un documento de 1229 , se menciona una parellada en Beniguerau, la cual limitaba al sur con una acequia y Alcántara (a meridie in chechia et in Alcantara) y al este con la vía que se dirigía a Alcántara (in via qua transitur aput Alcantaram) (TTE: 35). Estas referencias demuestran la proximidad de los lugares designados con esos topónimos. El puente ha de referirse al que atravesaba el barranco de Sant Antoni antes de desembocar en el Ebro.

Solo la algezira mencionada y dos piezas, una en Giramascor y otra en Alcántara limitaban con el río, a levante (CTT: 26 y 89). Un solo documento cita tres algeziras en Beniguerau, pero sin detalles en cuanto a su situación ni otros elementos del paisaje (DCT 2: 743).

El repartimiento y las posteriores transacciones a favor de la Sede de Tortosa, y en especial, de la encomienda del Temple de Tortosa, dieron lugar a la redacción de documentos que han puesto de relieve alrededor de cuarenta poseedores de parcelas. ${ }^{25}$ Todas son calificadas de terra o de campus, de lo que se deduce que la tierra se destinaba de manera preferente a la siembra de cereales o no estaban en cultivo. No consta un solo huerto, aunque la mención de un pozo podría indicar la presencia de otros, asociados a huertos dispersos.

En esta zona, también se mencionan diversas acequias. Consta una acequia mayor al oeste de un campo, y por tanto, paralela al Ebro (DCT 1: 212), y otra

25 El Temple adquirió seis inmuebles mediante cuatro compras (CTT: 26, 32, 44 y 45), una permuta (CTT: 74) y una donación (CTT: 126). En esas adquisiciones se observa una clara estrategia de concentrar las parcelas, puesto que la mayoría tenían otras piezas de la orden en sus límites. 
acequia al lado de un campo en Beniguerau, perpendicular al río. ${ }^{26}$ En documentos del siglo XIII figuran acequias en los límites de un campo adyacente al Ebro, y de una pieza de tierra en Giramascor (DCT 3: 1041; TTE: 109). La ausencia de menciones a huertos parece indicar que las acequias no se utilizaban para regar, sino para drenar, y el hecho que una de ellas sea calificada de mayor le confiere la función de captación de otros canales secundarios que vertían el agua a la principal. De hecho, existen referencias al prado en este sector meridional, por tanto, una zona inculta y con vegetación natural; una pieza de tierra lindaba con un cañaveral (in cannar). ${ }^{27}$

Sólo consta una acequia que no era de drenaje: la que procedía de Marenxa y desembocaba en el Ebro en Algezira Mascor: cequia illa maiori inferius que descendit de Marenxa et venit per Algevira Mazcor ad Yberum (DCT 1: 398). La prospección ha dado las claves de su función: abastecer un molino harinero llamado de Sedó, situado en la parte baja de su recorrido. En el Llibre del Pastoret, del siglo XVI, se menciona una acequia procedente del Canyeret de Maranxa hasta el camino de Sedó. ${ }^{28}$ Por lo tanto, la acequia procedente de Marenxa solo puede ser esta. ${ }^{29}$

El elevado número de islas fluviales sería coherente con la descripción de los paisajes situados justo al norte, en la llanura de Castellnou, como de humedal fluvial. Al sur de la llanura, junto al barranco de Sant Antoni, la aportación de sedimentos de este barranco y la creación de brazos fluviales en la parte baja habría propiciado la formación de islas con suficiente estabilidad como para que llegaran a tener incluso un topónimo, como Algezira Mascor (o Giramascor) (Figura 6).

Este paisaje tenía continuidad hacia el sur a través de la orilla fluvial, en los asentamientos y espacios agrarios discontinuos de Vinallop y Mianes. Las características eran las mismas: la existencia de un parcelario limítrofe con el Ebro, a tenor de las lindes, con menciones exclusivamente de campos y piezas de tierra y ausencia absoluta de huertos y viñas. La existencia de acequias, una de ellas calificada como mayor, revela un sistema de drenaje de esta zona de prado en la desembocadura de los barrancos del Roer y del Pasqualet.

26 ACA. Órdenes Militares, Gran Priorat, Tortosa, Códice 115, d. 3, f. 2v.

27 ACA. Órdenes Militares, Gran Priorat, Tortosa, Códice 115, d. 109, f. 34r.

28 Este códice desapareció del Archivo Municipal de Cantavieja durante la Guerra Civil de 1936-1939. Existe una copia mecanografiada en el Museu de les Terres de l'Ebre (Amposta): MTE. Llibre del Pastoret, ps. 100-102.

$29 \mathrm{~J}$. Negre considera que esta acequia era captada mediante un azud en el río Ebro, aguas arriba (Negre, 2014 y 2015). Su interpretación es completamente errónea. Ver la crítica detallada en Kirchner y Virgili (2019). 


\subsection{Las algeziras de la margen izquierda}

a) La algezira de Som y Tivenys

En la documentación de los siglos XII y XIII, Som y Tivenys constituyen dos grandes espacios de cultivo. El primero está asociado a un asentamiento andalusí de altura (en el cerro del coll de Som), donde existe un yacimiento con restos de cerámica y muros. Bajo dominio cristiano parece que no se reocupó el núcleo. Tivenys, en cambio, era una alquería (se menciona la mezquita) y consta como una villa a partir de la conquista. En la actualidad, Som pertenece al término municipal de Tivenys.

Antes se ha hecho mención a una algezira situada entre Xerta y Tivenys, que pasó bajo dominio de la sede de Tortosa y que fue colonizada a partir de sus iniciativas. En otros documentos consta, al menos, otra algezira situada entre Som y Tivenys. En 1178, Pere Joan retuvo una algezira al vender sus inmuebles de Som y Tivenys (DCT 1: 295). Asimismo, en 1231, el maestro Guillem, en su testamento, dispone que sus albaceas rediman una algezira que tenía en prenda el judío Bonafós por el prior de Tortosa (DCT 3: 908). Esta orden debió cumplirse, ya que en 1272, el prior del cabildo figuraba como poseedor de una algezira en Tivenys (DCT 3: 1326). No existe ninguna información respecto de la explotación agraria de esta pieza y no es posible localizarla en el valle fluvial.

\section{b) La algezira de Bítem}

Bítem era una alquería andalusí con un espacio agrario caracterizado por la variedad de sus cultivos, entre los que destacaban huertos, viñas y árboles, y donde el regadío se efectuaba con el agua de pozos elevada mediante norias (Kirchner y Virgili 2019). En 1154, Ramon Berenguer IV donó al obispo y a la catedral de Tortosa un campo en Bítem que había pertenecido al gobernador andalusí de Tortosa (quod in tempore sarracenorum fuit regis), y añadía la parte que había pertenecido a Gandulfo Carbonera en aquel lugar, en el caso de poderla conseguir (si predicta ecclesia ... de Gandulfo Carbonera partem suam quoquomodo adquirere poterit, illud ... dono et concedo) (DCT 1: 47). Esta posibilidad se hizo realidad, ya que en 1173 se confirmó la existencia de un campo situado en Bítem y también una ínsula en poder de la sede de Tortosa, que habían pertenecido antes a los genoveses Martí Gòlia y Gandulf Carbonera (DCT 1: 244). El documento no explicita que la ínsula estuviera en Bítem, pero es muy probable que así fuera, a tenor de un documento anterior que menciona la existencia de un campo de estos dos individuos lindante con la orilla del Ebro (DCT 1: 56), y no ofrece información sobre si estaba o no en cultivo. Actualmente, existe una gran isla fluvial ante Bítem, llamada Isla de Audí, pero no se puede asegurar que se trate de la misma o que sus contornos sean los mismos de la que se menciona en el siglo XII. 


\section{c) La algezira de Abnabicorta}

Los documentos contemporáneos a la conquista designan el espacio agrario situado al norte del muro septentrional de la ciudad como huerta de Pimpí (orta de Pimpino, Pampino, Punpí). Ante este espacio se extiende una isla fluvial llamada de Jesús o Xiquina, topónimo que designa también la parte meridional de orilla izquierda de Pimpí (playa de la Xiquina). Es posible que esta isla corresponda a la algedira de Abnabicorta, adjudicada, juntamente con la atarazana y otros bienes, a la comunidad judía de Tortosa por Ramon Berenguer IV, en noviembre de 1149 (CPFC: 76). En la isla constan cinco huertos, cuyos dueños andalusíes son identificados en el texto. No existe ninguna otra referencia a esta isla, ni el topónimo, ni alienaciones documentadas que afectaran alguno de estos huertos. Desconocemos si esta algezira tiene alguna relación con la que consta en sendos documentos fechados en 1241, en los que un herreñal situado en Vimpeçol lindaba a poniente con una algezira, llamada de Sant Llorenç (DCT 3: 1005 y 1006). ${ }^{30}$ Vimpeçol era la puerta del muro septentrional de la ciudad de Tortosa, y daba nombre también al sector adyacente y en contacto con la huerta de Pimpí.

\section{d) La algezira de las Arenes}

Arenes es el topónimo que en los documentos de los siglos XII y XIII designaba la gran llanura que ocupa el meandro que traza el Ebro justo al sur de Tortosa, en la orilla izquierda. Este espacio estaba equipado con una red ortogonal de acequias de drenaje con el fin de evacuar el agua que aportaban los barrancos y el propio río al desbordarse el cauce; destacan las menciones a tierras y campos (asociados a tierras eventualmente destinadas al cultivo de cereales) y a viña, cuyo cultivo se potenció tras la conquista (Virgili, 2010; Puy, Balbo, Virgili Kirchner, 2014). En 1159, Guerau de Salvanyac obtenía mediante permuta un campo con un pozo (campum cum puteo) y una alzezira que formaba parte de una heredad en las Arenas que había poseído un sarraceno escribano, de nombre Galib; el campo y la algezira estaban separados por una acequia: et cum isto campo tenet se alzezira ista una esequia media (DCT 1: 97). No existen referencias al río ni ninguna pista que permita su localización.

En 1230, Dolça, esposa de Ramon de Conies, vendió a Maria de Calders una viña con dos algeziras; el conjunto estaba situado en Arenes, en el lugar llamado Cony de Vaca (Vulva Vacce) ${ }^{31}$ no localizado, pero en sus límites no constan ni el Ebro ni acequias; sí un camino que va a la fuente (DCT 3: 905), de la cual tampoco tenemos noticias, y no parece haber contacto ni cercanía con la algezira anterior.

30 Sant Llorenç, en este caso, no puede identificarse con la reseñada insula Iberis, adherida ya a la orilla derecha.

31 Uno de los cajones del ACT, donde se custodia este documento, lleva la etiqueta Cony de Vaca, topónimo que hoy no se conserva. 


\section{e) La algezira de Aquilen (Campredó)}

$\mathrm{Al}$ sur de las Arenes se extiende otra llanura fluvial caracterizada por ser una zona de prado, con la existencia de numerosos manantiales de agua que surge del subsuelo debido a la proximidad de acuíferos y de la capa freática; en la región se conocen con el nombre de ullals. Los topónimos reflejados en la documentación de los siglos XII y XIII son Aquilen (también Aguilen y Aquileny), Quint (o Quinto) y Pedrera, que hoy se asocian al núcleo de Campredó (EMD del municipio de Tortosa). En este espacio las parcelas son calificadas de tierra y campo casi en su totalidad, por tanto, eventualmente roturables. La catedral de Tortosa y la encomienda del Temple acumularon un extenso patrimonio en este sector.

El 3 de noviembre de 1196, Bernat de Godall vendió a Ramon de Xerta la algezira de Aguilen, un espacio rodeado por el Ebro, excepto por el lado oriental, donde se mencionan unas honores. ${ }^{32}$ Un documento de 1243 se refiere a la alienación de una honor en el que constan tierra cultivada y yerma, plantas, árboles, acequias y fuentes, tal vez referidas a los manantiales (ullals). Al describir el límite occidental indica la presencia del Ebro y la algezira de Joan Arnau, que antes había sido de Albert de Xerta, tal vez un hijo del Ramon de Xerta, quien la había comprado inicialmente (DCT 3: 1037 y 1132). Ambas menciones se refieren, inequívocamente, a la misma algezira.

Ramon de Tons delimitó la honor en parcelas que estableció a campesinos. En los límites de éstas figuran el Ebro, siempre a occidente, y la algezira de Joan Arnau (DCT 3: 1241). Asimismo, se menciona una acequia del mismo Joan Arnau, casi con toda seguridad, un canal de drenaje. (DCT 3: 1274 y 1277).

Otros documentos del primer cuarto de la centuria siguiente confirman la ubicación del espacio de cultivo de Aguilen, que se extendía hasta la orilla del Ebro, y cuyas piezas se distribuían entre una red de acequias. A principios del siglo XIV, se formalizaron establecimientos sobre piezas de tierra campa citra Iberis [...] in algira nostra. ${ }^{33}$ Entre los límites constaban el Ebro y acequias: una de ellas era la cequia vocata mare. En 1356, Arnau de Prat, procurador del prior, establecía in enphiteosim ad bene laborandum a Berenguer Arnau dos porciones de tierra campa con plantas y árboles, in partita de Aguilleyn. ${ }^{34}$ Los límites precisan la situación de estas piezas: confrontatas in cequia de la mare departin ab la alguira.

Posiblemente, la situación de este espacio, encajonado entre el río y las acequias, le confiere el carácter de isla (algira, algeira o algezira), y se trata de la misma ya mencionada en los documentos del siglo XII. Y esta acequia llamada "madre" no es otra que la acequia mayor, el colector principal de una red de canales de drenaje.

32 ACA. Órdenes Militares, Gran Priorat, Tortosa, Códice 115, d. 159, f. 52r.

33 ACT. Cajón 53, Coves de Naguillem, etc., perg. s. n. (tres pergaminos, inéditos).

34 ACT. Cajón 53, Coves de Naguillem, etc., perg. s. n. (pergamino inédito) 


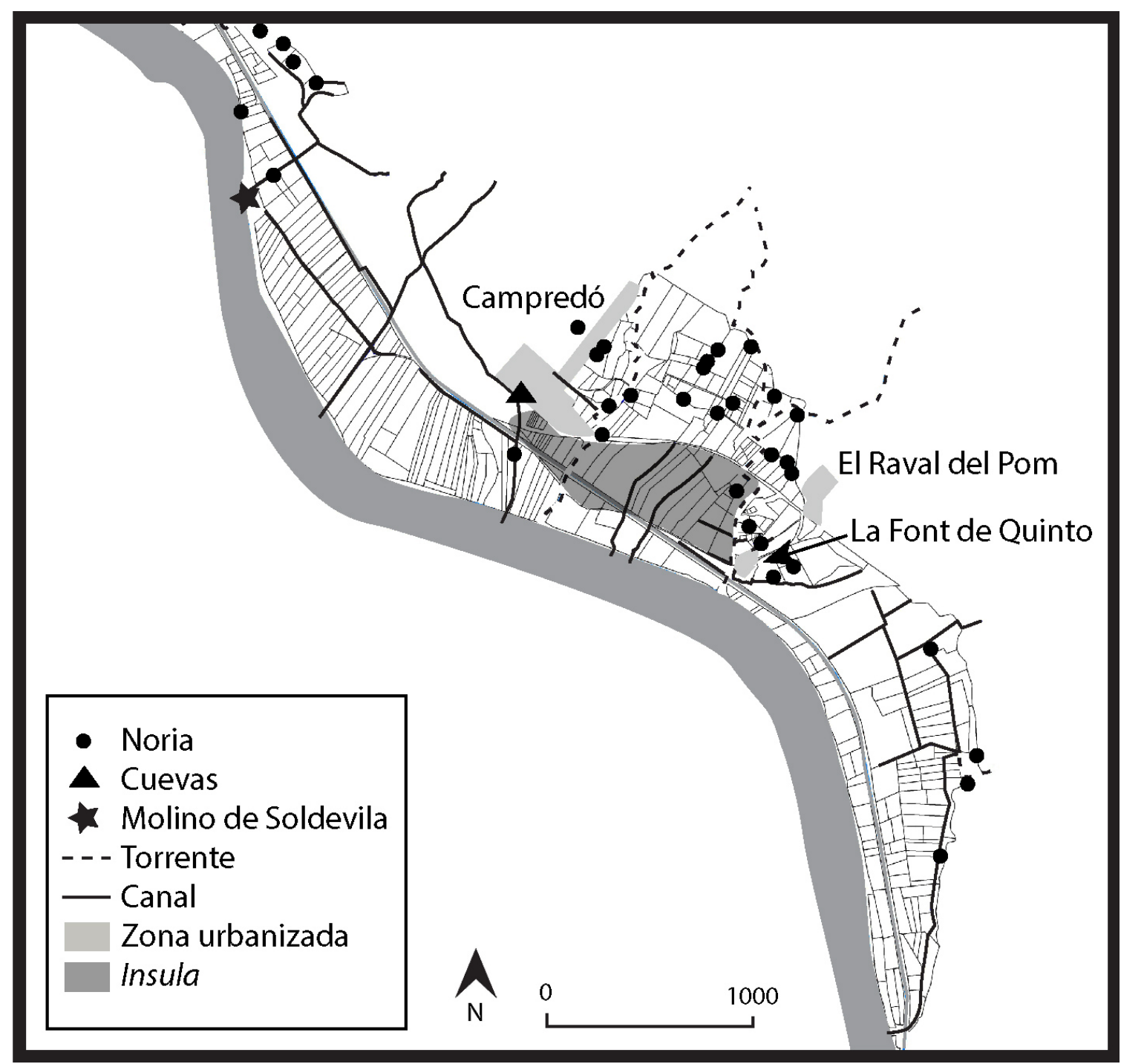

Figura 7. La algezira de Aquilen (Campredó).

El espacio situado entre las acequias y el Ebro es lo que los documentos designan con el nombre de algezira. La construcción de esta infraestructura habría permitido el acceso a este espacio, tanto para aprovechar los recursos del prado, como para poner en marcha un proceso de colonización agraria como el que impulsaron los conquistadores. Es plausible que la algezira corresponda a una franja de tierra firme situada entre la acequia y el río, con un límite redondeado y fosilizado en un camino que lleva el significativo nombre de Camí de Salvaigües y encajada entre la desembocadura de dos torrentes (Figura 7).

\section{CONCLUSIONES}

En el momento de proceder al repartimiento y ocupar los parcelarios andalusíes del curso bajo del Ebro, los conquistadores cristianos se encontraron con un nombre 
de origen árabe, algezira (isla), utilizado para designar unos espacios de ribera rodeados en parte por el cauce. Se trataba de paquetes de sedimentación depositados por el Ebro en zonas de pronunciados meandros y, a menudo, estaban adheridos a la orilla por uno de sus límites, aunque también podían estar separados de ésta por un canal fluvial, el alfalig (o galacho). En los sectores objeto de estudio, las grandes algeziras y sus componentes más llamativos, los galatxos, están situados sobre todo en la orilla derecha del Ebro. Así parece ocurrir también más al norte, en la comarca de la Ribera del Ebro, aunque faltan estudios para poderlo afirmar de manera fehaciente. Algunos de estos espacios de ribera han podido ser bien localizados e, incluso, delimitados. Se trata especialmente de aquellas algeziras que han quedado adheridas a la ribera por uno de sus lados, formando parcelarios con una morfología característica (de forma redondeada, de huso alargado o de abanico), en los meandros y en las desembocaduras de los torrentes.

Por su proximidad al cauce, las algeziras estaban muy expuestas al impacto de la corriente cuando se producían grandes avenidas, y sujetas a procesos de erosión o sedimentación, tal como lo recogen los textos. Por lo que hemos observado en el Baix Ebre, estas islas también se formaban cerca de la desembocadura de algunos barrancos. En los sectores más meridionales del curso bajo del río, al sur de Tortosa, los documentos califican de prado a amplios sectores de la llanura fluvial. Eran zonas eventualmente inundadas por las aguas de los torrentes, del propio río o por la presencia de aguazales. A menudo, la gestión de estos espacios húmedos requería la construcción de una red de acequias de drenaje para hacerlos accesibles y eliminar los excesos de agua. Así se ha constatado, por ejemplo, en Algezira Mascor (o Giramascor), en la orilla derecha, en las Arenas o en Aquilen (Campredó), en la izquierda, donde la algezira parece estar encajonada entre las acequias y el Ebro.

Tal vez por tratarse de espacios poco estables, parece que en época andalusí las algeziras, salvo excepciones como la de Abnabicorta, no fueron objeto de cultivo permanente, sino de aprovechamiento de los recursos naturales que ofrecía la vegetación de ribera, especialmente, pastos. Tras la conquista, los señores feudales impulsaron significativas transformaciones en los espacios agrarios; una de estas consistió en la ampliación del área de cultivo para extender los cereales y la viña de manera preferente, unos procesos que afectaron de manera especial las áreas de prado, hacia la llanura deltaica, pero también las de ribera, como las algeziras. Los procesos de colonización agraria de las algeziras estudiadas se produjeron décadas después de la conquista, ya a partir del siglo XIII, como hemos visto en Xerta y Aquilen, bajo el impulso del cabildo de Tortosa, o en la insula Iberis por parte de la encomienda del Temple, a medida que se asentaban nuevos colonos cristianos en la región y aumentaba la demanda de recursos. 


\section{REFERENCIAS BIBLIOGRÁFICAS}

\section{SIGLAS Y FUENTES PRIMARIAS}

CDRG: Imperiale di Sant'Angelo, C. (1936). Codice Diplomatico della Repubblica di Genova dal MCLXIIII al MCLXXXX, Roma: Istituto Storico Italiano.

CP: Pons Marquès, J. (1938). Cartulari de Poblet. Edició del manuscrit de Tarragona. Barcelona: Institut d'Estudis Catalans.

Costums: Massip, J. (ed.) (1996). Costums de Tortosa. Barcelona: Fundació Noguera. CPFC: Font Rius, J. M. (1969). Cartas de población y franquicias de Cataluña, 2 vols. Madrid - Barcelona: CSIC.

CTT: Pagarolas, L. (1984). La Comanda del Temple de Tortosa, primer període (11481213). Tortosa: Dertosa.

DCT 1: Virgili, A. (1997). Diplomatari de la catedral de Tortosa (1062-1193). Barcelona: Fundació Noguera.

DCT 2: Virgili, A. (2001). Diplomatari de la Catedral de Tortosa (1193-1212). Episcopat de Gombau de Santaoliva. Barcelona: Fundació Noguera.

DCT 3: Virgili, A.; Escolà, J. M.; Pica, M. y Rovira, M. (2018). Diplomatari de la Catedral de Tortosa. Episcopats de Ponç de Torrella (1212-1254) i Bernat d'Olivella (1254-1272). Barcelona: Fundació Noguera.

DCVB: Alcover, A. M., Moll, F. de B. (1988). Diccionari català - valencià - balear. Palma de Mallorca: Ed. Moll.

DSC: Papell, J. (2005). Diplomatari del monestir de Santa Maria de Santes Creus (9751225), Barcelona: Fundació Noguera.

TTE: Pagarolas, L. (1999). Els Templers de les Terres de l'Ebre (Tortosa): de Jaume I fins a l'abolició de l'Orde: 1213-1312, 2 vols, (vol. 2). Tarragona: Diputació de Tarragona.

\section{BIBLIOGRAFÍA}

BonachíA, J. A. (2012). El agua en las Partidas. En M.I. del Val Valdivieso, J.A. Bonachía (Coord.), Agua y sociedad en la Edad Media hispana (p. 13-64). Granada: Universidad de Granada.

Bramon, D. (2012). Reivindicació catalana del geògraf al-Idrisi. Discurs de recepció de Dolors Bramon i Planas com a membre numerària de la Secció Històrico- Arqueològica, llegit el dia 20 de novembre de 2012. Barcelona: Institut d'Estudis Catalans.

CurTo, A. (1993). Notes biogràfiques de l'antic pont de Tortosa. En AADD. Lo pont de barques. L'antic pas de l'Ebre a Tortosa. Barcelona: Llibres de l'Índex.

Del Val VAldivieso, M. I. (2012). El agua en los fueros medievales de la corona castellana. En M.I. del Val Valdivieso, J.A. Bonachía (Coord.), Agua y sociedad en la Edad Media hispana (p. 64-94). Granada: Universidad de Granada. 
FABREGAT, E. (2006). Burgesos contra senyors. La lluita per la terra a Tortosa (11481299). Tortosa: Arxiu Comarcal de les Terres de l'Ebre; Consell Comarcal del Baix Ebre.

FABREGAT, E. y VidAL, J. (2007). La canalització de l'Ebre a la regió de Tortosa (13471851). Quaderns de la història de la enginyeria, (8), 3-49.

Frago, J. A. (1979). Toponimia navarroaragonesa del Ebro. I. Islas y señales de delimitación del terreno. Príncipe de Viana, 154-155, 51-64.

Hermon, E. (2014). Concepts environnementaux et la gestión integrée des bords de l'eau (riparia) dans l'Empire Romain: Une leçon du passé? En E. Hermon \& A. Watelet (Dirs.), Riparia, un patrimoine culturel: La gestión intégrée des bords de l'eau: Actes de l'atelier Savoirs et practiques de gestión intégrée des bords de l'eau: Riparia, Sudbury, 12-14 avril 2012 (pp. 9-18). Oxford: BAR International Series, Archeopress. https://doi.org/10.30861/9781407312156

KIRCHNER, H. (en prensa). Hydraulic technology as means of Christian colonisation. Watermills and channels in the Lower Ebro (Catalonia). World Archaeology.

KirChner, H. y Virgili, A. (2018). Espacios agrarios en el Bajo Ebro en época andalusí y después de la conquista catalana (siglos XI-XIII). En J. Torró, J. y Guinot, E. (eds). Trigo y ovejas. El impacto de las conquistas en los paisajes andalusíes (siglos XI-XVI) (pp. 15-49), València: PUV.

KirChner, H. y Virgili, A. (2019). Espacios de cultivo vinculados a Madînat Turțūša (Tortosa, Cataluña): norias, drenajes y campesinos (siglos VIII-XII). Edad Media. Revista de Historia, (20), 83-112. https://doi.org/10.24197/em.20.2019.83-112

Kirchner, H., Virgili, A. y Antolín, F. (2014). Un espacio de cultivo urbano en alAndalus: Madînat Țurțū̌a (Tortosa) antes de 1148. Historia Agraria, 62, 11-45. En H. Kirchner, A. Virgili, M. Rovira y M. Pica (2020). Espais agraris de l'entorn del castell de Miravet abans i després de la conquesta cristiana (segles X-XVII). Miscel.lània del CERE, 30 (pp. 249-272).

LACÁMARA, D. (2020). La ruptura de un equilibrio. El siglo XV y la paulatina ocupación y degradación de los espacios naturales zaragozanos. Espacio, Tiempo y Forma, (13), 169-189. https://doi.org/10.5944/etfvi.13.2020.25526

Marfull, J. (2014). Un sistema hidráulico feudal en el valle del Segre: la acequia de Torres. En C. Sanchis Ibor, G. Palau-Salvador, I. Mangue Alférez, L. Pablo Martínez; Th. F. Glick (Eds.). Irrigation, society and landscape: tribute to Thomas F. Glick: proceedings [of the] International Conference, Valencia, September 25th, 26th and 27th (p. 155-171), València: Editorial Universitat Politècnica de València.

MARTí, R. (1988). Les insulae medievals catalanes. Bolletí de la Societat Arqueològica Lul.liana, 44, 111-123.

Miravall, R. (1998). Dellà lo pont de barques, Tortosa: Dertosa. 
Monjo, M. (2012). La pervivencia del regadío andalusí en la Aitona bajomedieval. En J. Torró y E. Guinot (Eds.). Hidráulica agraria y sociedad feudal: prácticas, técnicas, espacios (pp. 207-224), València: PUV.

NAJES, L.; Ollero, A.; SÁnCheZ, M. (2019). Evolución y dinámica geomorfológica actual del río Ebro en la Reserva Natural Dirigida de los Sotos y Galachos (Zaragoza). Cuaternario y Geomorfología, 1-2, 47-64. https://doi.org/10.17735/ cyg.v33il-2.67874

NegRe, J. (2014). Poblamiento rural en el distrito islámico de Turtuša: resultados de las campañas de prospección arqueológica en les Terres de l'Ebre (2010-2011). En F. Sabaté, J. Brufal (dirs.). La Ciutat Medieval i Arqueologia, VI Curs Internacional d'Arqueologia Medieval (pp. 241-262). Lleida: Pagès Editors.

Negre, J. (2015). Origen y desarrollo de la huerta de Tortosa (siglos IV-XII). El proceso de formación de un macro-espacio irrigado en el levante peninsular. Historia Agraria, (66), 11-40.

Pellicer, F. (2018). Los paisajes del Ebro en las puertas de la Ciudad de Zaragoza. En F. J. Monclús y C. Díez (eds.), Ciudad y formas urbanas. Perspectivas transversales. Vol. 7: Formas urbanas, paisaje, ecourbanismo (pp. 117-131). Zaragoza: Prensas de la Universidad de Zaragoza; Institución Fernando el Católico. https://doi.org/10.18172/cig.948

Pellicer, F. y YeTANo, M. L. (1985). El galacho de Juslibol. Un ejemplo de meandro abandonado. Cuadernos de Investigación Geográfica, 11, 113-124.

Puy, A., Balbo, A., Virgili, A. y Kirchner, H. (2014). Wetland reclamation in alAndalus. The drainage of Les Arenes floodplain (Tortosa, Spain, 7th-10th centuries AD). Geoderma, 232-234, 219-235. https://doi.org/10.1016/j.geoderma.2014.05.001

RoYo, V. (2020). Ganadería e integración del espacio regional: la organización y la gestión de las pasturas en las fronteras de la Corona de Aragón, siglos XII-XIV. Historia Agraria, (80), 1-33.

TONEATtO, L. (1982). Note sulla tradizione del Corpus agrimensorum Romanorum. I. Contenuti e struttura dell'Ars gromatica di Gisemundus (IX sec.). Mélanges de l'École Française de Rome, 94 (1), 191-313. https://doi.org/10.3406/mefr.1982.2645 TORRó, J. (2010). Tierras ganadas. Aterrazamiento de pendientes y desecación de marjales en la colonización cristiana del territorio valenciano. En H. Kirchner (ed.). Por una arqueología agraria: perpectivas de investigación sobre espacios de cultivo en las sociedades medievales hispánicas (pp. 157-172). Oxford: BAR International Series, Archeopress.

TORRó, J. (2016). Agricultural drainage technology in medieval Mediterranean Iberia (13th-16th centuries). J. Klápste (ed.). Agrarian technology in the Medieval landscape, (pp. 309-323). Ruralia X. Turnhout: Brepols.

https://doi.org/10.1484/M.RURALIA-EB.5.110474 
TORRÓ, J. (2019). Paisajes de frontera: Conquistas cristianas y transformaciones agrarias (siglos XII al XIV). Edad Media. Revista de Historia, (20), 13-46. DOI: https://doi.org/10.24197/em.20.2019.13-46.

VIDAL, J. (2008). Les obres de la ciutat. Lactivitat constructiva de la Universitat de Tortosa a la baixa edat mitjana. Barcelona: Publicacions de l'Abadia de Montserrat. VIDAL, J. (2010). La continuidad de una obra medieval: azud, acequias, molinos y pesquera del Bajo Ebro en la época del Renacimiento. Quaderns d'Història de l'Enginyeria, (11), 129-174.

Virgili, A. (2010). Espacios drenados andalusíes y la imposición de las pautas agrarias feudales en el prado de Tortosa (segunda mitad del siglo XII). En H. Kirchner (ed.). Por una arqueología agraria: perspectivas de investigación sobre espacios de cultivo en las sociedades medievales hispánicas (pp. 147-155). Oxford: BAR International Series, Archeopress.

ViRGILI, A. (2019). Els primers processos de colonització agrària del prat de Tortosa: l'Aldea (segles XII-XIII). Afers, (34), 453-478.

Virgili, A. (2020). Conquista feudal y transformaciones agrarias: colonización agrícola y ganadería en el prado de Tortosa, siglos XII-XIII. Historia Agraria, (81), 1-30. https://doi.org/10.26882/histagrar.081e05v

Virgili, A. y Kirchner, H. (2019). The impact of the Christian conquest on the agrarian areas in the low Ebro valley. The case of Xerta (Spain). En N. Brady and C. Theune (eds.). Settlement Change Across Medieval Europe. Old Paradigms and New Vistas (pp. 413-420), Ruralia XII. Leiden: Sidestone press Academia.

Virgili, A., MATEU, M. y PACHECO, N. (2020). Els paisatges agraris del curs baix de l'Ebre a l'edat mitjana. En Autores Diversos. Paisatge històric i canvi climàtic (pp. 207-238). Tarragona: Arxiu Històric Arxidiocesà de Tarragona. Silva Editorial. 